\title{
Topological rearrangement yields structural stabilization and interhelical distance constraints in the Kin.46 self-phosphorylating ribozyme
}

\author{
BONGRAE CHO ${ }^{1}$ and DONALD H. BURKE ${ }^{2}$ \\ ${ }^{1}$ Department of Applied Chemistry, Division of Applied Science, Cheongju University, Cheongju 360-764, Korea \\ ${ }^{2}$ Department of Molecular Microbiology \& Immunology and Department of Biochemistry, University of Missouri, School of Medicine, \\ Columbia, MO 65211-7310, USA
}

\begin{abstract}
The Kin.46 ribozyme catalyzes transfer of the gamma (thio)phosphoryl group of ATP (or ATP $\gamma$ S) to the ribozyme's 5' hydroxyl. Single-turnover catalytic activities of topologically rearranged versions of Kin.46 were studied to gain insight into its overall tertiary architecture. The distal ends of stems P3 and P4 were tethered through a single-stranded connection domain that altered the interhelical connectivity. The shortest linkers interfered with catalysis, while seven or more nucleotides (nt) in the linker allowed near-normal catalytic rates, suggesting that a distance of roughly 25-35 $\AA$ optimally separates the termini of these helices. Activity was maximal when the tether contained $15 \mathrm{nt}$, at which point the $\mathrm{k}_{\text {cat }}\left(0.016 \mathrm{~min}^{-1}\right)$ and $\mathrm{K}_{\mathrm{m}}(1.2 \mathrm{mM}) \mathrm{values}$ were identical to those of a nontethered control. The presence of the tether alters $\mathbf{M g}^{2+}$ dependence, in that $\mathrm{Mg}^{2+}$ binding appears to be more cooperative in the tethered ribozyme (Hill coefficient 1.4-1.8 versus 0.8 for the nontethered ribozyme). Binding affinity for the ATP $\gamma \mathrm{S}$ substrate increases at elevated concentrations of $\mathrm{Mg}^{2+}$, particularly for the tethered ribozyme. The tethered ribozyme displays significantly enhanced thermal stability, with a maximum initial velocity $\left(0.126 \mathrm{~min}^{-1}\right)$ at $60^{\circ} \mathrm{C}$, whereas the nontethered ribozyme has a lower maximum initial velocity $\left(0.051 \mathrm{~min}^{-1}\right)$ at $50^{\circ} \mathrm{C}$. The tether also significantly reduces the apparent entropy of activation. Both of these effects can be understood in terms of stabilization of the ribozyme in a conformation that is on-path with respect to catalysis, and in terms of facilitating formation of the allosteric activation helix P4.
\end{abstract}

Keywords: ribozyme; thermostability; autokinase; tertiary structure; distance constraints; Eyring analysis

\section{INTRODUCTION}

Long-range interactions are essential for establishing the overall folds in many functional RNAs, and they strongly influence their physical, biochemical, and biological properties. For example, dramatic reductions in the $\mathrm{Mg}^{2+}$ concentration required for half-maximal activity $\left(\left[\mathrm{Mg}^{2+}\right]_{1 / 2}\right)$ have been observed by us (Saksmerprome et al. 2004; Greathouse and Burke 2005; Roychowdhury-Saha and Burke 2006) and by others (Khvorova et al. 2003; Canny et al. 2004; Penedo et al. 2004) for various hammerhead ribozymes upon inclusion of tertiary interactions between

Reprint requests to: Donald $H$. Burke, Department of Molecular Microbiology \& Immunology and Department of Biochemistry, University of Missouri, School of Medicine, Columbia, MO 65211-7310, USA; e-mail: burkedh@missouri.edu; fax: (573) 884-9676.

Article published online ahead of print. Article and publication date are at http://www.rnajournal.org/cgi/doi/10.1261/rna.173506. stems I and II. Tertiary contacts account for thermal stability in RNase P from thermophyllic bacteria (Baird et al. 2006) and increase thermal stability in the hammerhead ribozyme RzB (Saksmerprome et al. 2004). Mutants of Group I self-splicing introns that were selected for compact folds also demonstrated greater thermal stability than the less compact versions (Juneau and Cech 1999). Tertiary constraints can also reduce conformational heterogeneity to yield molecules more suitable for crystallization and structural analysis.

The stabilization afforded by native tertiary contacts can in some cases be replaced with alternative or artificial moieties that serve similar functions. In collaboration with Khvorova and Jayasena (Saksmerprome et al. 2004), we reported the in vitro selection of nonnatural sequences that functionally replaced the tertiary contacts between loops I and II of hammerhead ribozymes from peach latent mosaic viroid (PLMVd) and from Schistosoma mansonii. 
A long-range pseudoknot interaction within Escherichia coli RNase P is functionally replaced in Bacillus subtilis RNase $\mathrm{P}$ by a topologically unrelated element that nevertheless adopts essentially the same structure (Haas et al. 1991). Even short alkyl chains can tether ribozyme helices. Uhlenbeck and coworkers found that the internal equilibrium of hammerhead ribozyme catalysis shifted toward ligation (versus cleavage) in a covalently tethered ribozyme, and Sigurdsson and coworkers have compared the catalytic activities of covalently tethered hammerhead and hairpin ribozymes to aid in computational modeling of folding and docking within these RNAs (Sigurdsson et al. 1995; Earnshaw et al. 1997; Borda and Sigurdsson 2005).

Analysis of natural ribozymes has revealed many principles underlying the molecular basis for catalysis by biologically derived RNA enzymes. Biological evolution has extensively refined the subtle interplay among active site geometry, cofactor recruitment, gross three-dimensional fold, and the folding landscape. Some of these principles will also apply to evolutionarily emergent catalysts such as those derived from in vitro selections and ribozymes that may have been associated with an RNA world. Variations on the SELEX strategy have identified a flood of new artificial ribozymes that catalyze nearly all of the core reactions of genetic information transfer and several model reactions related to secondary metabolism, albeit at subbiological rates (for review, see Burke 2004). There has been considerable progress toward elucidating the structural basis of a ligase ribozyme (Bergman et al. 2004), a DielsAlderase ribozyme (Keiper et al. 2004; Serganov et al. 2005), and a nuclease DNAzyme (Nowakowski et al. 2000), but there is much less information for most of the other artificial ribozymes.

Phosphoryl transfer is among the most ubiquitous of biological reactions, yielding essential intermediates in energy transduction, biosynthesis, catabolism, and enzyme regulation. Ribozymes and DNAzymes with autophosphorylation activity have been isolated in several laboratories. Some of these molecules catalyze phosphorylation of 5 '-terminal hydroxyl groups (Lorsch and Szostak 1994; Li and Breaker 1999; Wang et al. 2002), while others target internal 2' hydroxyl groups (Lorsch and Szostak 1994; Curtis and Bartel 2005; Saran et al. 2005). During the isolation of the Kin.46 ribozyme, the evolving RNA library was incubated with ATP $\gamma \mathrm{S}$. A small fraction of the RNA species promoted transfer of the $\gamma$-thiophosphoryl group from ATP $\gamma \mathrm{S}$ onto themselves, thereby becoming tagged with a unique sulfur that enabled recovery via disulfide bond formation with a solid support. The Kin.46 ribozyme was identified as one of several species that autothiophosphorylated its $5^{\prime}$ terminal OH (Lorsch and Szostak 1994).

Several features of Kin.46 structure contribute to catalysis. The secondary structure includes four base-paired stems (P1 through P4) connected by unpaired joining regions and loops (J1/2, J2/3, L3, J3/2, J2/1, and J1/4)
(Fig. 1). Formation of $\mathrm{P} 1$ positions the $5^{\prime} \mathrm{OH}$ acceptor in the active site. The connection between $\mathrm{P} 1$ and J1/2 can be severed, such that the phosphorylation substrate becomes a 7 nucleotides (nt) acceptor strand that base-pairs to an internal guide sequence (IGS) and is subject to multiple turnover, intermolecular catalysis (Lorsch and Szostak 1995). For convenience, we refer to this arrangement as "TransKin.46" (Fig. 1). Non-Watson-Crick interactions within P1 appear to be essential, as replacing the terminal $\mathrm{G} \cdot \mathrm{U}$ pair with a $\mathrm{G} \cdot \mathrm{C}$ pair eliminates catalytic activity (Lorsch and Szostak 1995). Paired regions P2 and P3 and the joining regions between them were derived from a heavily mutagenized ATP aptamer included within the library during the original selection of Kin.46 (Lorsch and Szostak 1994). It is unclear whether this segment participates in ATP binding; however, ATP recognition by Kin.46 is clearly distinct from ATP recognition by the original aptamer. Key nucleotides required for ATP recognition by the aptamer are mutated in Kin.46, and the values of $\mathrm{K}_{\mathrm{m}}{ }^{\text {ATP } \gamma \mathrm{S}}$ and $\mathrm{K}_{\mathrm{m}}{ }^{\text {ATP }}$ for Kin.46 ( 3 mM) (Lorsch and Szostak 1994; Rhee and Burke 2004) are $>10^{3}$ times greater than $\mathrm{K}_{\mathrm{d}}^{\text {ATP }}$ for the aptamer $(\sim 1 \mu \mathrm{M})$ (Sassanfar and Szostak 1993). Stem P4 is formed upon binding of a DNA oligonucleotide to the sequence used in the amplification steps during the original selection for activity. Omitting the oligonucleotide reduces the catalytic rate constant $\left(\mathrm{k}_{\mathrm{cat}}\right)$ by $10^{3}$ - to $10^{6}$-fold, indicating that the oligo acts as an allosteric effector that is necessary for full catalytic activity (Lorsch and Szostak 1994). Detailed mutational and thermodynamic dissection of this allostery and of the roles of the single-stranded regions will be presented elsewhere (D.H. Burke and S.S. Rhee, in prep.).

There are no published data addressing the overall architecture of Kin.46 or any of the other artificially selected kinase ribozymes. To address this question, the present study examines the impact of tertiary constraints on the kinetic behavior of Kin.46. The distance between P3 and $\mathrm{P} 4$ was estimated by joining these two stems through a series of single-stranded "connector sequences," thereby altering the folding topology of the ribozymes and constraining the P3-P4 through-space distance. The kinetic parameters, thermodynamic parameters, and thermal stabilities of tethered and nontethered variants of Kin.46 were compared under the various conditions of ATP $\gamma \mathrm{S}$ concentration, $\mathrm{Mg}^{2+}$ concentration, and temperature. These data allow us to constrain the three-dimensional architecture of Kin.46, and to ascertain the effects of these topological constraints on ribozyme stability.

\section{RESULTS}

\section{Design and construction of Kin.46 variants}

The Kin.46 kinase is a self-(thio)phosphorylating ribozyme: it catalyzes the transfer of the $\gamma$-thiophosphoryl group from 


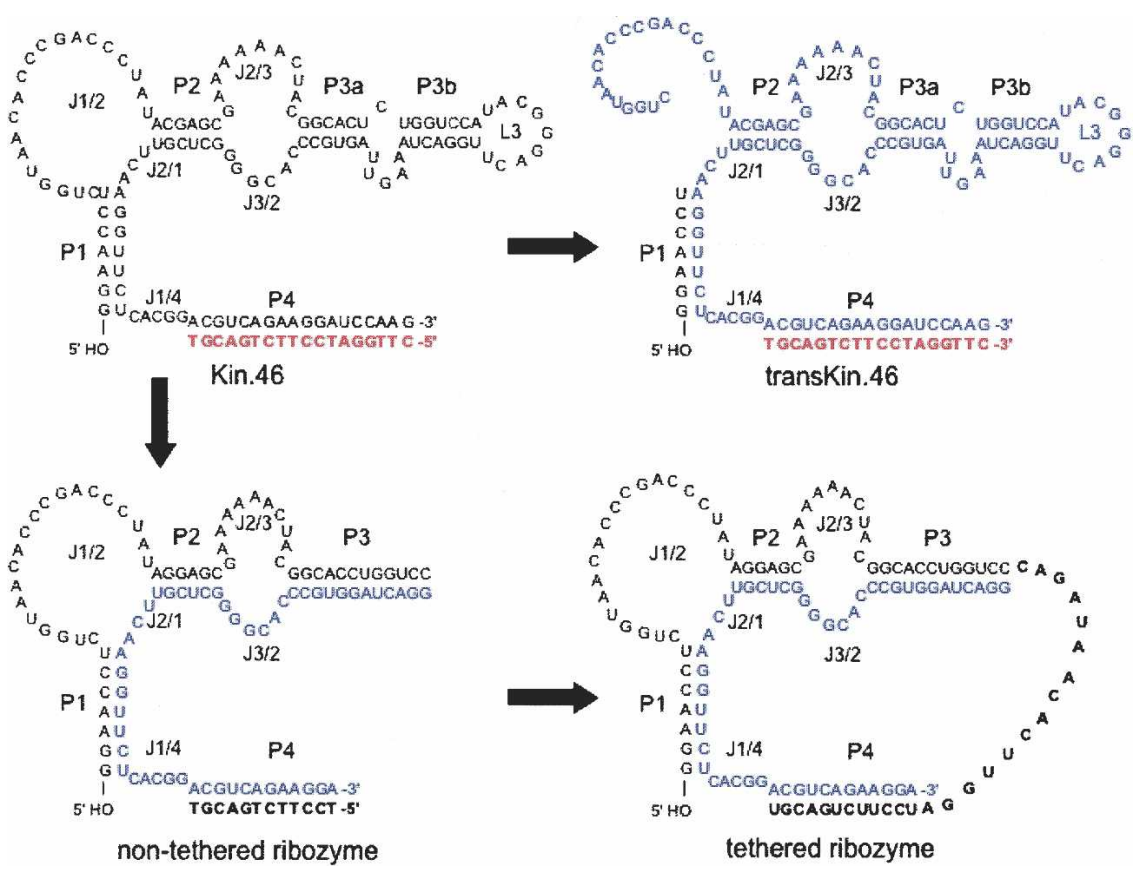

FIGURE 1. Secondary structure models of kinase ribozymes. Top line depicts ribozymes Kin.46 and TransKin.46 described previously (Lorsch and Szostak 1994, 1995). Bottom line depicts nontethered and tethered ribozymes derived from Kin.46 (15-nt tether shown). Paired elements P1 through P4, connecting loop L3, and joining elements J1/2, J2/3, J3/2, J2/1, and $\mathrm{J1} / 4$ are indicated. Each complex is built from two or three strands. In each structure, the strand that becomes thiophosphorylated is shown in black letters. For structures in which the complex contains two RNA strands, the other ribozyme strand is shown in blue. Effector oligodeoxynucleotide (where present) are shown in red.

ATP $\gamma \mathrm{S}$ (or of a phosphoryl group from ATP) onto its own 5 '-hydroxyl terminal group. In the parental Kin.46 ribozyme, stem P3 is separated by a small asymmetric bulge into two paired segments (P3a and P3b). A simplified variant of Kin.46 was generated by removing the bulges in P3, omitting nucleotides from loop 3 (L3), and replacing about half of P3 with unrelated base-paired nucleotides (Fig. 1). The resulting "nontethered" ribozyme was assembled in three pieces from a 56-nt " 5 ' RNA," a 51-nt " 3 ' RNA," and a 12-nt effector strand (5'-TCCTTCTGACGT- 3 '). In this arrangement, the $5^{\prime}$ RNA strand acts both as phosphorylation acceptor substrate and as part of the ribozyme. A series of tethered ribozymes was obtained by transcribing the 5' RNA transcript from templates that appended one of several connector segments and the effector oligo sequence (in RNA form) onto its 3' end. We have observed that RNA and DNA effector strands are essentially equivalent in terms of their ability to activate catalysis (D.H. Burke and S.S. Rhee, in prep.). This arrangement connects the termini of helices P3 and P4 with a single-stranded loop (Fig. 1).

\section{Determination of kinetic parameters}

Autothiophosphorylation rates were measured for the nontethered ribozyme $\left(0.0159 \pm 0.0009 \mathrm{~min}^{-1}\right)$ and for eight tethered variants with connecting loops varying in length from 1 to $20 \mathrm{nt}$. The tethered ribozyme with the shortest connection domain (1 nt) was barely active, with a catalytic rate reduced by nearly two orders of magnitude $(0.0002$ $\min ^{-1}$ ) relative to the nontethered species. This loss of activity can be understood in terms of either of two models. In the first, the formation of stem P4 pulls stems $\mathrm{P} 3$ and $\mathrm{P} 4$ too close together, distorting the active site by closing the angle between them. In the second model, the connector is simply too short to accommodate both P3 and P4 within the same folded structure. The values of $k_{\text {cat }}$ increased with the length of the connection loop, with nearly full activity recovered when the tether reached a length of $7 \mathrm{nt}$. A 7-nt connector is therefore long enough to accommodate the optimal spacing between the termini of P3 and P4. While is it formally possible that inhibitory, misfolded structures form in the presence of the shortest tethers, and that these structures are actively disrupted by the longer tethers, a more straightforward explanation is that the longer tethers allow the ribozyme to relax into an active fold by simultaneously forming stems P3 and P4 in a manner that can assume productive orientations with respect to each other. Activity is maximal for the ribozyme with the 15-nt connector (Fig. 2), so this construct was chosen for further study.

To ensure that gross ribozyme architecture was not significantly distorted by the presence of the tether, kinetic parameters for the self-thiophosphorylation reaction were compared for the nontethered ribozyme and for the tethered ribozyme with $15 \mathrm{nt}$ in the connecting loop.

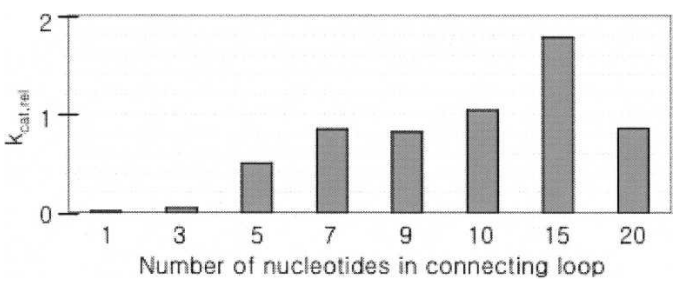

FIGURE 2. Relative $\mathrm{k}_{\mathrm{cat}}$ values $\left(\mathrm{k}_{\mathrm{cat}, \mathrm{rel}}=\mathrm{k}_{\mathrm{cat}}\right.$ tethered $^{\mathrm{k}} \mathrm{k}_{\mathrm{cat}}$ nontethered $)$ for self-thiophosphorylation with ATP $\gamma S$ for tethered ribozymes according to the size of the loop connecting helices P3 and P4. Nucleotide sequences in connecting loop are as follows; $1 \mathrm{nt}, \mathrm{A} ; 3 \mathrm{nt}$, GGA; $5 \mathrm{nt}$, UUGGA; 7 nt, ACUUGGA; 9 nt, ACACUUGGA; 10 nt, AACACUUG GA; 15 nt, CAGAUAACACUUGGA; 20 nt, AAUAACAGAUAACACU UGGA. 
Values for $\mathrm{k}_{\mathrm{cat}}$ and $\mathrm{K}_{\mathrm{m}}$ were determined by measuring the initial velocity of the reaction at various ATP $\gamma S$ concentrations and applying Michaelis-Menten analysis (Table 1). The values of $\mathrm{k}_{\mathrm{cat}}$ and $\mathrm{K}_{\mathrm{m}}$ are almost identical for the two ribozymes, suggesting that the tethered and nontethered forms are structurally and functionally equivalent at the catalytic core. In contrast, annealing a 13-nt DNA oligonucleotide complementary to the 15-nt tether reduced the observed catalytic rate by approximately sevenfold (data not shown), demonstrating that an A-form helical connection between the termini of P3 and P4 is not tolerated. Shorter oligos (11, 9, and $7 \mathrm{nt}$ ) had progressively less effect on catalysis, but they also did not remain bound in a native gel shift assay, and may have been excluded from the complex.

\section{Tether increases overall thermal stability}

As noted in the introduction, tertiary stabilization can markedly stabilize ribozyme structures against thermal denaturation. To determine whether similar stabilization is conferred by the tether between stems P3 and P4, initial reaction rates for the tethered and nontethered versions of the Kin.46 ribozyme were compared over a temperature range of $37^{\circ} \mathrm{C}-70^{\circ} \mathrm{C}$ (Fig. $3 \mathrm{~A}$ ). For the nontethered ribozyme, initial velocity increased slightly as the temperature was raised to $50^{\circ} \mathrm{C}\left(0.051 \pm 0.003 \mathrm{~min}^{-1}\right)$, then fell at higher temperatures. In contrast, initial velocities for the tethered ribozyme increased much more rapidly and reached a maximum at $60^{\circ} \mathrm{C}\left(0.126 \pm 0.011 \mathrm{~min}^{-1}\right)$. The single-stranded loop connecting helices P3 and P4 therefore confers enhanced thermal stability to the tethered ribozyme.

\section{Enthalpies and entropies of activation}

To determine $\Delta \mathrm{H}^{\ddagger}$ and $\Delta \mathrm{S}^{\ddagger}$ between the ground state and transition state, initial rate constants were measured from $15^{\circ} \mathrm{C}$ to $30^{\circ} \mathrm{C}$ and analyzed according to the Eyring relation (see Materials and Methods) (Fig. 3B). For the nontethered ribozyme-catalyzed reaction, the slope of the plot of the

\begin{tabular}{|c|c|c|c|c|}
\hline & $\begin{array}{c}{\left[\mathrm{Mg}^{2+}\right]} \\
(\mathrm{mM})\end{array}$ & $\mathrm{k}_{\text {cat }}\left(\min ^{-1}\right)$ & $\begin{array}{c}\mathrm{K}_{\mathrm{m}}{ }^{\text {ATP } \gamma \mathrm{S}} \\
(\mathrm{mM})\end{array}$ & $\mathrm{k}_{\mathrm{cat}} / \mathrm{K}_{\mathrm{m}}$ \\
\hline \multirow[t]{2}{*}{ Nontethered } & 50 & $0.0159(0.0009)$ & $1.2(0.2)$ & 0.013 \\
\hline & 300 & $0.084(0.009)$ & $0.9(0.3)$ & 0.093 \\
\hline \multirow[t]{2}{*}{ Tethered (15 nt) } & 50 & $0.016(0.002)$ & $1.2(0.5)$ & 0.013 \\
\hline & 300 & $0.151(0.003)$ & $0.3(0.2)$ & 0.50 \\
\hline TransKin.46 & 50 & 0.17 & 3.1 & 0.055 \\
\hline
\end{tabular}

${ }^{\mathrm{a} A l l}$ values are the averages of two independent assays. Standard errors (in parentheses) are the errors of the fit to the MichaelisMenten equation.

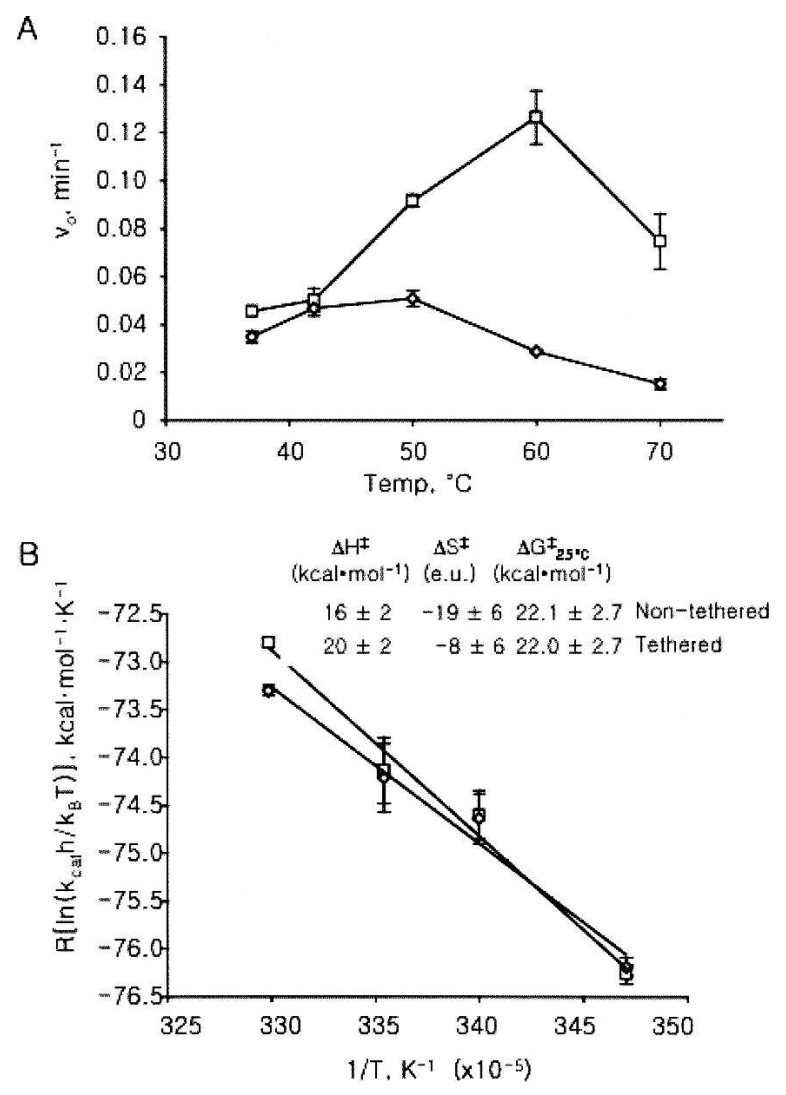

FIGURE 3. Temperature dependences of the tethered and the nontethered ribozymes. (A) Enhanced thermal stability for the tethered ribozyme. The initial velocity is plotted as a function of assay temperature. Squares indicate the tethered ribozyme (15-nt connector) and diamonds indicate the nontethered ribozyme. Errors bars are shown when greater than the size of the symbols. (B) Eyring analysis for the self-thiophosphorylation of the tethered and the nontethered ribozyme. $\mathrm{k}_{\mathrm{cat}}$ is the calculated rate constant for the reaction at the indicated temperatures, $h$ is the Planck constant, $\mathrm{k}_{\mathrm{B}}$ is the Boltzmann constant, and $\mathrm{T}$ is the absolute temperature. All units are standard SI units. Squares indicate the tethered ribozyme and diamonds indicate the nontethered ribozyme. Plotted values are the averages of three separate experiments. Activation energy parameters are given above the plot, calculated from the slope $\left(-\Delta \mathrm{H}^{\ddagger}\right)$ and extrapolated $\mathrm{y}$-intercept $\left(\Delta \mathrm{S}^{\ddagger}\right)$ as described in Materials and Methods.

temperature dependence of the initial rate gives $\Delta \mathrm{H}^{\ddagger}=$ $16 \pm 2 \mathrm{kcal} / \mathrm{mol}$, and the extrapolated $\mathrm{y}$-intercept gives $\Delta \mathrm{S}^{\ddagger}=-19 \pm 6 \mathrm{eu}$. The enthalpy of activation measured here is more unfavorable, and the entropy of activation is less unfavorable, than the values reported for the TransKin.46 ribozyme $\left(\Delta \mathrm{H}^{\ddagger}=11 \pm 1 \mathrm{kcal} / \mathrm{mol}\right.$ and $\Delta \mathrm{S}^{\ddagger}=-33 \pm$ $3 \mathrm{eu}$ ) (Lorsch and Szostak 1995). Activation entropy is further reduced for the reaction catalyzed by the tethered ribozyme, for which $\Delta \mathrm{H}^{\ddagger}=19 \pm 2 \mathrm{kcal} / \mathrm{mol}$ and $\Delta \mathrm{S}^{\ddagger}=$ $-8 \pm 6$ eu. Both the tethered and nontethered ribozymes have almost identical Gibb's free energies of activation at $25^{\circ} \mathrm{C}\left(\Delta \mathrm{G}_{25^{\circ} \mathrm{C}}=21.4 \pm 2.7\right.$ and $21.7 \pm 2.7 \mathrm{kcal} / \mathrm{mol}^{-1}$, respectively) within error, consistent with their nearly identical $\mathrm{k}_{\text {cat }}$ values. 


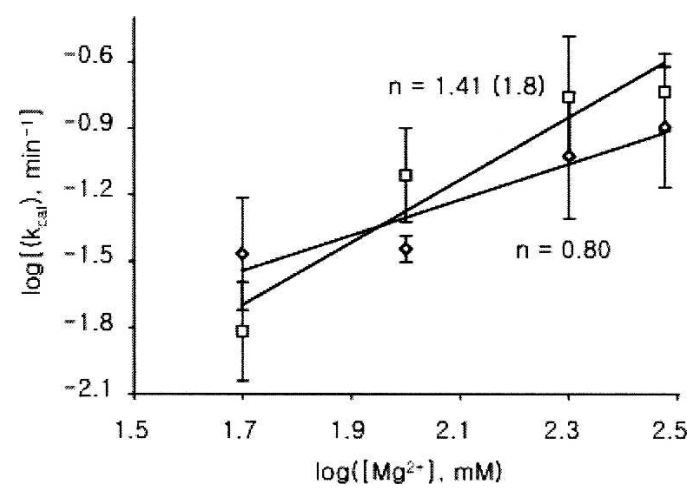

FIGURE 4. $\mathrm{Mg}^{2+}$ dependence of the initial velocities of both nontethered and tethered ribozyme. Squares indicate the tethered ribozyme (15-nt connector) and diamonds indicate the nontethered ribozyme. Plotted values are the averages of two separate experiments. Hill coefficients $(n)$ were found from the slopes of the graphs using all four data points. For the tethered ribozyme, the value shown in parenthesis was obtained when only the first three data points were used in calculating the Hill coefficient.

\section{$\mathrm{Mg}^{2+}$ dependence of kinase ribozymes}

Changes in ribozyme tertiary organization can dramatically affect metal ion utilization. The Kin.46 ribozyme was initially selected in the presence of $50 \mathrm{mM} \mathrm{MgCl}_{2}$ (Lorsch and Szostak 1994). The $\mathrm{Mg}^{2+}$ dependence of the catalytic activities of nontethered and tethered ribozymes were therefore measured as a function of $\mathrm{Mg}^{2+}$ concentration (Fig. 4). When the concentration was reduced to $10 \mathrm{mM}$, the RNA-catalyzed signal was indistinguishable from background. Initial velocities increased for both ribozymes as $\mathrm{Mg}^{2+}$ concentration was increased. The tethered ribozyme appears to be saturated above $200 \mathrm{mM} \mathrm{Mg}{ }^{2+}$, while the nontethered ribozyme is still rising at $300 \mathrm{mM} \mathrm{Mg}{ }^{2+}$. Interestingly, the initial velocity increases more steeply with $\mathrm{Mg}^{2+}$ for the tethered ribozyme than for the nontethered control, and the velocities achieved at the highest $\mathrm{Mg}^{2+}$ concentrations are $50 \%$ greater for the tethered species than for the nontethered one. Hill coefficients (n) for $\mathrm{Mg}^{2+}$ utilization were determined from the slope of a plot of $\log (\mathrm{k})$ as a function of the $\log$ of the $\mathrm{Mg}^{2+}$ ion concentration. The value of $\mathrm{n}$ is near unity for the nontethered ribozyme (0.8), but is significantly greater for the tethered ribozyme (1.4), particularly if the $300 \mathrm{mM}$ data point is omitted (1.8). Omitting this data point from the analysis may be justified if the ribozyme is saturated in this range. Thus the tethered ribozyme appears to bind $\mathrm{Mg}^{2+}$ more cooperatively, and may utilize a second metal ion to achieve the transition state.

To explore the mechanistic basis for this apparent enhancement in $\mathrm{Mg}^{2+}$-binding cooperativity, the MichaelisMenten kinetic parameters of both ribozymes were obtained at $50 \mathrm{mM}$ and $300 \mathrm{mM} \mathrm{Mg}^{2+}$ by measuring the substrate dependence of the initial velocity at each condi- tion (Table 1). At $50 \mathrm{mM} \mathrm{Mg}^{2+}$, both ribozymes have essentially identical $\mathrm{K}_{\mathrm{m}}{ }^{\mathrm{ATP} \gamma \mathrm{S}}$ and $\mathrm{k}_{\mathrm{cat}}$ values. Previous studies found that $\mathrm{k}_{\mathrm{cat}} / \mathrm{k}_{-1}$ is $\sim 10$ for TransKin.46, indicating that $\mathrm{K}_{\mathrm{m}}{ }^{\mathrm{ATP} \gamma \mathrm{S}} \approx \mathrm{K}_{\mathrm{d}}{ }^{\mathrm{ATP} \gamma \mathrm{S}}$. This relation also holds for the tethered and nontethered versions of Kin.46, for which $\mathrm{k}_{\text {cat }}$ values are $\sim 10$-fold slower than for TransKin.46. Both the rate constants and the apparent binding affinity for ATP $\gamma S$ increase for both ribozymes at $300 \mathrm{mM} \mathrm{Mg}{ }^{2+}$ relative to the corresponding values in $50 \mathrm{mM} \mathrm{Mg}^{2+}$. The increase in catalytic efficiency $\left(\mathrm{k}_{\mathrm{cat}} / \mathrm{K}_{\mathrm{m}}{ }^{\mathrm{ATP} \gamma \mathrm{S}}\right)$ is sevenfold for the nontethered ribozyme and $>37$-fold for the tethered ribozyme. Although most of the increased efficiency comes from a greater improvement in ATP $\gamma S$-binding affinity in the tethered variant, this parameter is expected to have minimal relevance at saturating concentrations $(10 \mathrm{mM})$ of ATP $\gamma$ S. Therefore, the apparent increased cooperativity of $\mathrm{Mg}^{2+}$ binding may suggest that the tethered ribozyme is better able to utilize $\mathrm{Mg}^{2+}$ in the rate-limiting step(s) than is the nontethered ribozyme. Further work is needed to define the structural basis of the apparent change in $\mathrm{Mg}^{2+}$ utilization.

\section{DISCUSSION}

The present work provides the first assessment of the overall architecture of a kinase ribozyme. Changing the connectivity of the stems within ribozyme Kin.46 generated a tethered species that is functionally equivalent to the nontethered species under standard assay conditions. Very short tethers interfere with formation of an active structure, while medium-length tethers are compatible with activity, stabilize the ribozyme against thermal denaturation (Fig. $3 \mathrm{~A}$ ), and provide additional opportunities for $\mathrm{Mg}^{2+}$ utilization (Fig. 4). The tethered and nontethered ribozymes have almost identical $k_{c a t}$ and $K_{m}$ values within error range for the self-thiophosphorylation reaction with ATP $\gamma$ S. Further characterization of these ribozymes established the influence of this altered topology on thermodynamic stability, activation parameters, and divalent ion dependence. As detailed below, this study sheds light on the overall geometry of the ribozyme and on alterations in the activation parameters for transition state acquisition.

The dependence of activity on linker length suggests that long-range distance constraints can aid in delineating overall ribozyme geometry and tertiary structure. The shortest tether that allowed most activity to be restored was $7 \mathrm{nt}$ in length. A tether of this length is capable of spanning $\sim 35-40 \AA$ if fully extended (5-6 $\AA / n$ t for flexible chain) (Williams et al. 2001). Half of the normal activity was recovered for a 5-nt tether $(\sim 25-30 \AA)$. Assuming that neither connector is fully extended in the absence of a strong external stretching force, full extension is likely to be disfavored in either case. To a first approximation, then, the connector segment can be viewed as a single-stranded molecular ruler indicating an optimal distance of $\sim 25-35 \AA$ 
at the distal termini of $\mathrm{P} 3$ and $\mathrm{P} 4$. If it is assumed that the single-stranded regions $\mathrm{J} 2 / 3$ and $\mathrm{J} 3 / 2$ form part of the active site-potentially forming the ATP-binding element-and that the $5^{\prime} \mathrm{OH}$ acceptor must be brought into this active site, then it follows that the proximal termini of P3 and P4 must be close to each other in space, and that the helices angle away from each other to achieve the implicated interhelical distance (Fig. 5).

Topological alterations have been used in the construction of variants of well-studied ribozymes for basic science and biotechnology applications. For example, when Silverman and Cech tethered distant sites in the Group I intron from Tetrahymena with a photocleavable linker, the ribozyme was kept inactive until it was released from the tether, permitting an analysis of the folding pathway in an environment that does not include changes in $\mathrm{Mg}^{2+}$ concentrations (Silverman and Cech 1999, 2001; Silverman et al. 2000). "Half-ribozyme" biosensors were constructed by altering the connectivity of a ligase ribozyme so that they are activated upon the addition of zeptomole quantities of hepatitis C viral RNA (Vaish et al. 2003; Kossen et al. 2004). When topological rearrangements are used to extract distance constraint information from recently discovered or poorly characterized ribozymes, the information is necessarily of a lower resolution than that obtained from spectroscopic (FRET or EPR) and cross-linking strategies. Nevertheless, the strategy is readily generalized to ribozymes for which there is only minimal knowledge of functional sequences and secondary structures, requiring only the ability to assemble the ribozyme from multiple strands.

The tethered, nontethered, and TransKin.46 ribozymes all display negative entropies of activation, implying that the transition state is more ordered than the ground state. The magnitude of the entropy change required to reach the transition state is least for the tethered ribozyme and greatest for TransKin.46. Assuming that each reaction must pass through transition states that are ordered to an identical degree, the differences in $\Delta \mathrm{S}^{\ddagger}$ imply differences in the degree of on-path preordering in the respective ground states. Specifically, the tethered ribozyme is likely to be conformationally constrained in a manner that is most similar to the transition state, and TransKin.46 is the most disordered in its ground state. The very large value of $\Delta S^{\ddagger}$ for TransKin.46 led those authors to propose that an entro-

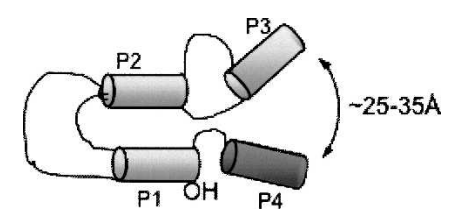

FIGURE 5. Schematic representation of spatial constraints within Kin.46. Cylinders represent helical elements and lines represent joining regions. pically disfavored conformational rearrangement may accompany the rate-limiting step (Lorsch and Szostak 1995). Our present data support that possibility, particularly if severing the connection between stem P1 and loop $\mathrm{J} 1 / 2$ increases the ground-state entropy in the transKin.46 ribozyme (Fig. 1). Our present data also suggest that the tethered ribozyme is pre-ordered for reaction, and that its enhanced thermal stability (above) derives in large part from positional constraints between helices P3 and P4, potentially restricting large-scale motions of the helices. Finally, the stabilization against thermal denaturation noted above can be understood as arising either from an increase in local concentration of effector sequence (stabilizing an essential secondary structure) or by preventing large-scale motions of the helices (stabilizing tertiary structure), as the entropy of activation for either mechanism is expected to be significantly reduced by the presence of the tether.

\section{MATERIALS AND METHODS}

\section{Materials}

Tris(2-carboxyethyl)phosphine (TCEP) was purchased from Pierce. The organomercurial compound, [(N-acryloylamino)phenyl] mercuric chloride, was synthesized from (4-aminophenyl) mercuric acetate (Aldrich) and acryloyl chloride (Fluka) following the procedure of Igloi (1988). All single-stranded DNAs, including transcription templates, were purchased from Integrated DNA Technologies (Coralville, IA). Recombinant T7 RNA polymerase and Taq DNA polymerase were purified from overproducing bacterial strains. The $\mathrm{pH}$ of ATP stock solution was adjusted to 7.0 with $\mathrm{NaOH}$. All other chemicals were purchased from Sigma (St. Louis, MO).

\section{Preparation of ribozymes}

Ribozyme strands were synthesized by run-off transcription of PCR DNA templates using T7 RNA polymerase. ${ }^{32} \mathrm{P}$ internally labeled $5^{\prime}$-RNA strand was synthesized by T7 RNA polymerase run-off transcription in the presence of $\left[\alpha-{ }^{32} \mathrm{P}\right] \mathrm{UTP}$. RNA transcripts were purified from $8 \%$ denaturing ( $7 \mathrm{M}$ urea) polyacrylamide gels using $90 \mathrm{mM}$ Tris-borate $(\mathrm{pH} 8.3)$ and $2.5 \mathrm{mM}$ EDTA, then they were dephosphorylated with calf intestinal alkaline phosphatase (CIP) (New England Biolabs). Then EDTA (5 $\mathrm{mM}$ final concentration) was added to the mixture, which was incubated at $75^{\circ} \mathrm{C}$ for $10 \mathrm{~min}$ to deactivate the CIP, followed by extraction with phenol/chloroform, precipitation with ethanol, and resuspension in water.

\section{Kinetic analysis}

Rates of RNA-catalyzed thiophosphoryl transfer were measured using internally ${ }^{32} \mathrm{P}$-labeled $5^{\prime}$-RNA strand, synthesized as internally radiolabeled transcript using $\left[\alpha-{ }^{32} \mathrm{P}\right] \mathrm{UTP}$. Active complex was assembled using $1 \mu \mathrm{M} 5^{\prime}$-strand and $2 \mu \mathrm{M} 3^{\prime}$-strand of ribozyme. For the nontethered form of the ribozyme, $4 \mu \mathrm{M}$ effector DNA oligomer (12-mer) was also included. The requisite 
strands were heated in $\mathrm{KCl} / \mathrm{PIPES}$ buffer $(200 \mathrm{mM} \mathrm{KCl}$ in $150 \mathrm{mM}$ PIPES, pH 7.0) at $90^{\circ} \mathrm{C}$ for $2 \mathrm{~min}$ and allowed to cool to room temperature $\left(\sim 21^{\circ} \mathrm{C}\right)$. TCEP (final concentration $10 \mathrm{mM}$ ) was added to maintain a reducing environment and to avoid disulfide bond formation between thiophosphorylated products (Rhee and Burke 2004; Saran et al. 2005). $\mathrm{MgCl}_{2}$ was added to yield a final concentration of $50 \mathrm{mM} \mathrm{MgCl} 2$ unless otherwise indicated, and an aliquot was immediately removed to serve as zero time point. Thiophosphoryl transfer was initiated by the addition of ATP $\gamma S$ (0.01-10 $\mathrm{mM})$ at room temperature. Aliquots were removed at various times, and the reaction was quenched on dry ice with 4 volumes of $94 \%$ formamide, $30 \mathrm{mM}$ EDTA ( $\mathrm{pH}$ 8.0) containing xylene cyanol and bromophenol blue. Thiophosphorylated product and unreacted nonthiophosphorylated 5' strands were separated by denaturing gel electrophoresis on a $6 \%$ trilayer gel containing $100 \mu \mathrm{g}$ APM/mL organomercurial polyacrylamide solution in the middle layer $(\sim 1 \mathrm{~cm})$. This design takes advantage of the strong interaction between mercury and thiolate ions (Igloi 1988) and has proven valuable for the selection and kinetic analysis of kinase ribozymes (Rhee and Burke 2004; Saran et al. 2005). Dried gels were exposed to storage phosphor screens and analyzed using ImageQuant software (Molecular Dynamics). Thiophosphorylation extent was calculated by dividing the radioactivity in the product band (retained at the top of the APM layer) by the sum of reacted and unreacted bands. Internally radiolabeled 5 '-strand RNA was terminally thiophosphorylated by polynucleotide kinase (New England Biolabs) and ATP $\gamma S$ to serve as normalization control in determining the fraction reacted for each of the experiments above. Apparent first-order rate constants $\left(\mathrm{k}_{\mathrm{cat}}\right)$ were calculated by fitting the fraction converted to product (y) to the equation:

$$
\mathrm{y}=\mathrm{y}_{\max }\left[\left(1-\exp \left(-\mathrm{k}_{\mathrm{cat}} \mathrm{t}\right)\right]\right.
$$

In all experiments, $\mathrm{y}_{\max }$ approached $100 \%$ in extended reactions, similar to previous observations (Lorsch and Szostak 1995). Values for $\mathrm{K}_{\mathrm{m}}$ were calculated by plotting the initial rate values to substrate concentration and fitting the data to the standard Michaelis-Menten relationship. All data fitting was done using Kaleidagraph (Synergy Software).

\section{Temperature dependence and Eyring analysis}

Apparent first-order rate constants were measured as a function of temperature essentially as above, using $10 \mathrm{mM} \mathrm{ATP} \gamma \mathrm{S}$ throughout. PIPES buffer was adjusted to $\mathrm{pH} 7.0$ with $\mathrm{KOH}$ at room temperature for reactions carried out at $15^{\circ} \mathrm{C}-30^{\circ} \mathrm{C}$ for Eyring analysis. To keep the buffer $\mathrm{pH}$ constant $(\mathrm{pH}$ 7.0) at higher temperatures $\left(37^{\circ} \mathrm{C}-70^{\circ} \mathrm{C}\right)$, PIPES buffers were $\mathrm{pH}$ adjusted to $\mathrm{pH}$ 7.0 at the temperature of the assay to control for the temperaturedependence of PIPES buffer.

Thermodynamic analysis was performed used the Eyring relation (for review, see Fersht 1999), which describes the temperature dependence of reaction rate in terms of the activation energy associated with accessing the transition state:

$$
\mathrm{k}=\mathrm{k}_{\mathrm{B}} \mathrm{T} / \mathrm{h} \exp \left(-\Delta \mathrm{H}^{\ddagger} / \mathrm{RT}\right) \exp \left(\Delta \mathrm{S}^{\ddagger} / \mathrm{R}\right)
$$

where $\mathrm{h}$ is the Planck constant, $\mathrm{k}_{\mathrm{B}}$ is the Boltzmann constant, $\mathrm{T}$ is the absolute temperature, and $\Delta \mathrm{H}^{\ddagger}$ and $\Delta \mathrm{S}^{\ddagger}$ are the enthalpy and entropy of activation. The values of $\Delta \mathrm{H}^{\ddagger}$ and $\Delta \mathrm{S}^{\ddagger}$ are determined from the slope and the intercept of the linear form of the Eyring equation, respectively:

$$
\mathrm{R} \ln \left[\mathrm{k}\left(\mathrm{h} / \mathrm{k}_{\mathrm{B}} \mathrm{T}\right)\right]=-\Delta \mathrm{H}^{\ddagger}(1 / \mathrm{T})+\Delta \mathrm{S}^{\ddagger}
$$

\section{ACKNOWLEDGMENTS}

Steven Rhee synthesized the APM used in this work and provided helpful observations and discussion throughout the project. This work was supported by Exobiology Award NAG5-12360 from NASA and by an Interdisciplinary Science Award from the David and Lucille Packard Foundation.

Received June 1, 2006; accepted September 6, 2006.

\section{REFERENCES}

Baird, N., Srividya, N., Krasilnikov, A., Mondragon, A., Sosnick, T., and Pan, T. 2006. Structural basis for altering the stability of homologous RNAs from a mesophilic and a thermophilic bacterium. RNA 12: 598-606.

Bergman, N., Lau, N., Lehnert, V., Westhof, E., and Bartel, D.P. 2004. The three-dimensional architecture of the class I ligase ribozyme. RNA 10: 176-184.

Borda, E. and Sigurdsson, S. 2005. Investigation of $\mathrm{Mg} 2+-$ and temperature-dependent folding of the hairpin ribozyme by photo-crosslinking: Effects of photo-crosslinker tether length and chemistry. Nucleic Acids Res. 33: 1058-1068.

Burke, D.H. 2004. RNA-catalyzed genetics. In The genetic code and the origin of life (ed. L. Ribas de Pouplana), Landes Bioscience, Austin, TX.

Canny, M.D., Jucker, F.M., Kellogg, E., Khvorova, A., Jayasena, S.D., and Pardi, A. 2004. Fast cleavage kinetics of a natural hammerhead ribozyme. J. Am. Chem. Soc. 126: 10848-10849.

Curtis, E. and Bartel, D. 2005. New catalytic structures from an existing ribozyme. Nat. Struct. Mol. Biol. 12: 994-1000.

Earnshaw, D., Masquida, B., Muller, S., Sigurdsson, S., Eckstein, F., Westhof, E., and Gait, M. 1997. Interdomain cross-linking and molecular modeling of the hairpin ribozyme. J. Mol. Biol. 274: 197-212.

Fersht, A. 1999. Structure and mechanism in protein science (A guide to enzyme catalysis and protein folding). W.H. Freeman and Company, New York.

Greathouse, S.T. and Burke, D.H. 2005. Low-magnesium, transcleavage activity by type III, tertiary stabilized hammerhead ribozymes with stem 1 discontinuities. BMC Biochem. 6: 14 .

Haas, E., Morse, D., Brown, J., Schmidt, F., and Pace, N. 1991. Long-range structure in ribonuclease P RNA. Science 254: 853856.

Igloi, G. 1988. Interaction of tRNAs and of phosphorothioatesubstituted nucleic acids with an organomercurial. Probing the chemical environment of thiolated residues by affinity electrophoresis. Biochemistry 27: 3842-3849.

Juneau, K. and Cech, T. 1999. In vitro selection of RNAs with increased tertiary structure stability. RNA 5: 1119-1129.

Keiper, S., Bebenroth, D., Seelig, B., Westhof, E., and Jaschke, A. 2004. Architecture of a Diels-Alderase ribozyme with a preformed catalytic pocket. Chem. Biol. 11: 1217-1227.

Khvorova, A., Lescoute, A., Westhof, E., and Jayasena, S.D. 2003. Sequence elements outside the hammerhead ribozyme catalytic core enable intracellular activity. Nat. Struct. Biol. 10: 708-712.

Kossen, K., Vaish, N., Jadhav, V., Pasko, C., Wang, H., Jenison, R., McSwiggen, J., Polisky, B., and Seiwert, S. 2004. High-throughput 
ribozyme-based assays for detection of viral nucleic acids. Chem. Biol. 11: 807-815.

Li, Y. and Breaker, R.R. 1999. Phosphorylating DNA with DNA. Proc. Natl. Acad. Sci. 96: 2746-2751.

Lorsch, J.R. and Szostak, J.W. 1994. In vitro evolution of new ribozymes with polynucleotide kinase activity. Nature 371: 31-36.

Lorsch, J.R. and Szostak, J.W. 1995. Kinetic and thermodynamic characterization of the reaction catalyzed by a polynucleotide kinase ribozyme. Biochemistry 34: 15315-15327.

Nowakowski, J., Shim, P., Stout, C., and Joyce, G. 2000. Alternative conformations of a nucleic acid four-way junction. J. Mol. Biol. 300: 93-102.

Penedo, J.C., Wilson, T.J., Jayasena, S.D., Khvorova, A., and Lilley, D.M.J. 2004. Folding of the natural hammerhead ribozyme is enhanced by interaction of auxiliary elements. RNA 10: 880-888.

Rhee, S. and Burke, D.H. 2004. Tris(2-carboxyethyl)phosphine (TCEP) stabilization of RNAs: Comparison with dithiothreitol (DTT) for use with nucleotide and thiophosphoryl chemistry. Anal. Biochem. 325: 137-143.

Roychowdhury-Saha, M. and Burke, D. 2006. Extraordinary rates of transition metal ion-mediated ribozyme catalysis. RNA 12: $1846-1852$.

Saksmerprome, V., Roychowdhury-Saha, M., Khvorova, A., Jayasena, S., and Burke, D.H. 2004. Artificial tertiary motifs stabilize trans-cleaving hammerhead ribozymes under conditions of submillimolar divalent ions and high temperatures. RNA 10: 1916-1924.

Saran, D., Nickens, D., and Burke, D. 2005. A trans acting ribozyme that phosphorylates exogenous RNA. Biochemistry 44: 15007-15016.

Saran, D., Held, D., and Burke, D. 2006. Multiple-turnover thioATP hydrolase and phospho-enzyme intermediate formation activities catalyzed by an RNA enzyme. Nucleic Acids Res. 34: 3201-3208.

Sassanfar, M. and Szostak, J.W. 1993. An RNA motif that binds ATP. Nature 364: 550-553.

Serganov, A., Keiper, S., Malinina, L., Tereshko, V., Skripkin, E., Hobartner, C., Polonskaia, A., Phan, A., Wombacher, R., Micura, R., et al. 2005. Structural basis for Diels-Alder ribozymecatalyzed carbon-carbon bond formation. Nat. Struct. Mol. Biol. 12: $218-224$.

Sigurdsson, S., Tuschl, T., and Eckstein, F. 1995. Probing RNA tertiary structure: Interhelical crosslinking of the hammerhead ribozyme. RNA 1: 575-583.

Silverman, S. and Cech, T. 1999. RNA tertiary folding monitored by fluorescence of covalently attached pyrene. Biochemistry 38: 14224-14237.

Silverman, S. and Cech, T. 2001. An early transition state for folding of the P4-P6 RNA domain. RNA 7: 161-166.

Silverman, S., Deras, M., Woodson, S., Scaringe, S., and Cech, T. 2000. Multiple folding pathways for the P4-P6 RNA domain. Biochemistry 39: 12465-12475.

Vaish, N., Jadhav, V., Kossen, K., Pasko, C., Andrews, L., McSwiggen, J., Polisky, B., and Seiwert, S. 2003. Zeptomole detection of a viral nucleic acid using a target-activated ribozyme. RNA 9: $1058-1072$.

Wang, W., Billen, L.P., and Li, Y. 2002. Sequence diversity, metal specificity, and catalytic proficiency of metal-dependent phosphorylating DNA enzymes. Chem. Biol. 9: 507-517.

Williams, M., Rouzina, I., Wenner, J., Gorelick, R., MusierForsyth, K., and Bloomfield, V. 2001. Mechanism for nucleic acid chaperone activity of HIV-1 nucleocapsid protein revealed by single molecule stretching. Proc. Natl. Acad. Sci. 98: 6121-6126. 

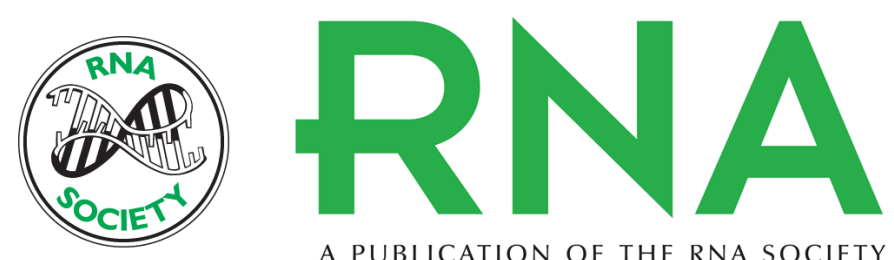

A PUBLICATION OF THE RNA SOCIETY

\section{Topological rearrangement yields structural stabilization and interhelical distance constraints in the Kin.46 self-phosphorylating ribozyme}

Bongrae Cho and Donald H. Burke

RNA 2006 12: 2118-2125 originally published online October 26, 2006

Access the most recent version at doi:10.1261/rna.173506

References This article cites 32 articles, 12 of which can be accessed free at:

http://rnajournal.cshlp.org/content/12/12/2118.full.html\#ref-list-1

License

Email Alerting Receive free email alerts when new articles cite this article - sign up in the box at the Service top right corner of the article or click here.

To subscribe to RNA go to:

http://rnajournal.cshlp.org/subscriptions 